\title{
Salpingite Amebiana
}

\author{
Dr. Carmo Lordy
}

Sob este titulo de todo original o Prof. Menetrier, nos “Archives de $\mathrm{Pa}$ rasitologie", de Paris, em data de 30 de Julho de 1910, relata a observação de um caso isolado e sem precedentes na literatura medica.

Trata-se de uma mulher de 26 annos de idade, que nunca sahira da França e que jamais fôra attingida de affecção dysenterica ou dysenteriforme, operada por Lejars, por uma salpingite dupla, remontando a diversos annos e de etiologia imprecisa. As duas trombas estavam affectadas e adherentes ao intestino. O ovario direito foi respeitado e o esquerdo extirpado com as duas trombas. A tromba esquerda, a unica examinada, macroscopicamente apresentava o aspecto de uma salpingite chronica com abundante vascularização dos tecidos, espessamento fibroso do orgão, sem dilatação da cavidade ou formação kystica, sem exsudato e sem suppuração cavitaria ou intersticial. Ao exame histologico, notava-se esclerose intensa pelo desenvolvimento de tecido fibroso adulto muito vascularizado e com espessamentó da parede. Ao nivel da mucosa, o auctor encontrou lesões para as quaes chama a attenção. As dobras da mucosa se apresentavam umais curtas, mais volımosas, augmentadas de espessura do logar de sua implantação para o centro da cavidade tubaria, a ponto de se obter formações com o aspecto de clavas. Este espessamento da mucosa era produzido pela infiltração sub-epithelial de grande numero de cellulas, que fixavam mal os corantes. Taes elementos cellulares de 25 a 30 micra, irregularmente esphericos, ás vezes deformados pela pressão reciproca, apresentavam um nucleo relativamente pequeno e abundante protoplasma. O nucleo quasi sempre excentrico corava-se fortemente e era arredondado. O protoplasma não corado tinha matiz amarellado, fixando em geral mal as substancias corantes, um pouco melhor as acidas, como a eosina.

Apresentava-se finamente granuloso e sem vacuolos distinctos. A mucosa parecia distendida pelo accumulo de taes cellulas, principalmente do lado cavitario, revestida por epithelio cylindrico ciliado com seu delgado estrato conjunctivo subjacente. Do lado muscular e sem ultrapassal-o estes elementos iam rareando de numero, acompanhados de uma reacção lymphocytaria. Na luz tubaria, no meio de um exsudato albuminoso coagulado e adherente á superficie da mucosa e de suas dobras notava-se numero reduzido destas mesmas cellulas. Para o auctor, taes elementos cellulares não se relacionavam com as cellulas epitheliaes, nem com as cellulas conjunctivas fixas e nem com as migradoras. A elle, estas cellulas se afiguravam como elementos heterogeneos, adventicios, parasitarios, multiplicados na superficie e na profundidade dos tecidos, provocando assim a alteração pathologica. A identificação destes parasitas era muito difficill, tanto mais que o auctor fez seu estudo sobre preparações já fixadas e coradas. Compa- 


\section{LORDY - Salpingite amebiana.}

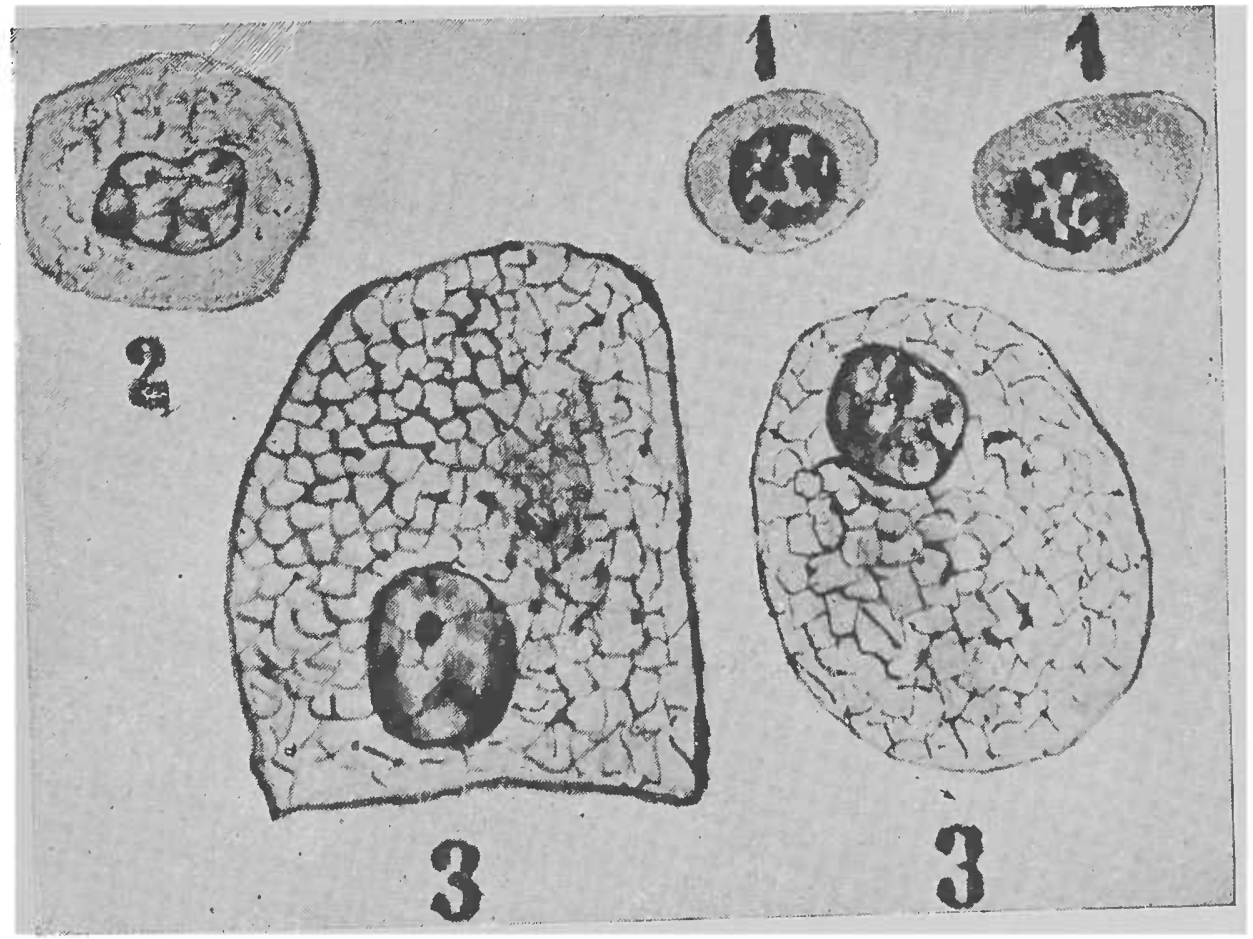

1 - Plasmazellen normaes e plasmazellen.

1 - Plasmazellen normaes e plasmazellen. ainda bastante corado, porém já esponjoso. Nucleo com afrouxamento da estructura chromatica.

3 - Cellulas pseudo-xanthomatosas.

Cellulas de una membrana pyo-nephritica. 

rando, porém, estes elementos cellulares com os causadores da dysenteria amebiana (particularmente num caso de um abcesso amebiano do figado com phagedenismo cutaneo), ao auctor pareceu possivel estabelecer grande analogia entre estes parasitas, plenamente identificados, e as cellulas grandes, globulosas, encontradas na tromba em questão. Desse cotejo elle crê dever concluir tratar-se de uma infecção das trombas uterinas por parasitas parecidos com as amebas, de uma salpingite amebiana. Diz poder expressar esta opinião com mais segurança por ter merecido a approvação do Prof. Blanchard, a quem submetteu pard exame suas preparações. Sómente não pode precisar si estes elementos são identicos ou não ás amebas pathogenas ou si se trata de uma especie nova.

Este trabalho, que por mera coincidencia cahiu sob nossa vistas, emquanto procuravamos referencias sobre outro assumpto que estavamos estudando, se presta admiravelmente bem para patentear até que ponto as apparencias e as analogias, a que o auctor se refere, podem falsear o diagnosticos e arrastar a enganos lastimaveis scientistas de vulto como os Profs. Menetrier e Blanchard.

Em primeiro logar, o nucleo das cellulas em questão, para maior analogia com o das amebas, deveria ter reticulo chromatico mais delgado e porisso corar-se muito menos intensamente; o protoplasma, por sua vez, com suas malhas deveria limitar vacuolos mais distinctos.

Os elementos cellulares que levaram o auctor e o emerito parasitologista a pensar em formações hețerogeneas, adventicias, sem apparencia com as cellulas normaes e pathologicas do orgão, não passam de elementos que se apresentam nos casos em que ha necrose e destruição dos tecidos com substancia graxa. São cellulas que se carregam de substancias isotropicas e principalmente anisotropicas (porisso de matiz amarellado quando não coradas), com protoplasma de finas ou grossas granulações (finos ou grossos vacuolos, quando não empregado o acido osmico ou o Sudan III) e que fixam geralmente mal a coloração commum. Apresentam-se intumescidas, com formato redondo, oval ou pela pressão reciproca mais ou menos achatadas, com nucleo geralmente de chromatina nem sempre condensada e excentrico. Estes elementos são encontrados em grande numero na periphèria de velhos fócos de suppuração, constituindo a membrana pyogena, côr de manteiga, da parede interna dos abcessos e em torno de focos diversos de necrose, denunciando a reabsorpção de substancias graxas.

Formam-se á custa principalmente de cellulas conjunctivas ou de plasmazellen e, pela grande semelhança com os elementos blastomatosos da xanthoma, são geralmente conhecidos com o nome de cellulas pseudo-xanthomatosas.

Segundo a exposição feita pelo auctor tem-se a impressão de se tratar de um caso de endosalpingite chronica, provavelmente gonococcica, em que se deu anteriormente a formação de puz com destruição mais ou menos liniitada da mucosa com seu epithelio de revestimento. 
Com a reabsorpção da substancia necrosada purulenta veiu a formação das cellulas pseudo-xanthomatosas e posteriormente a' regeneração do epithelio, como sóe acontecer nas inflammações purulentas e de modo especial nas de origem gonococcica.

$O$ que nas salpingites purulentas antigas parece macroscopicamente infiltração purulenta, conforme as recentes observações de Pich, não passa de accumulo de elementos cellulares volumosos, claros com substancias birefrangentes, isto é, de cellulas pseudo-xanthomatosas.

Não é necessario, portanto, invocar o concurso de elementos heterogeneos e parasitarios para explicar a presença destas cellulas, parecidas muito embora com as amebas. Assistimos apenas ao desempenho de uma funcção, de que são capazes as cellulas conjunctivas e, no nosso caso de provavel infeç̧ão gonococcica, principalmente as plasmazellen.

Resta ainda explicar como, quando e por onde se deu a infecção amebiana numa mulher que nunca sahira da França e que nunca soffréra alterações dysentericas ou dysenteriformes, como o proprio auctor affirma.

$\mathrm{Na}$ apreciação de um quadro morbido, mais do que o estudo de cada elemento, deve ser levado em conta o conjuncto das circumstancias e das alterações, não se preterindo nunca as relações entre os diversos processos.

Si esta não fôr a norma, a cada passo surgirão difficuldades de interpretação, dando em resultado diagnosticos esdruxulos, como o que estamos discutindo e que, no entanto, mereceu o placet do grande parasitollogista Blanchard.

Nos mesmos "Archives de Parasitologie" de 30 de Outubro de 1910, ha uma observação não menos interessante sobre este assumpto; feita por Duval e Lemarchal, com o titulo seguinte: Cellulas simulando amebas $e$ cancer de evolução normal.

Por uma puncção aspirada praticada num ganglio sub-maxillar mais ou menos fluctuante, os auctores acharam, em meio de neutrophilos alterados, cellulas grandes simulando amebas a ponto do Prof. Brumpt, a quem consultaram, achar, no principio, admissivel semelhante hypothese. Sómente, após exames repetidos de preparasões a fresco e coradas, o eximio parasitologista modificou seu parecer, fazendo notar entre outros caracteres differenciales a facil colloração dos nucleos, depois da fixação, destes grandes elementos cellulares. O exame histologico consecutivo veiu demostrar que se tratava de uma metastase ganglionar de um carcinoma planocellular corneificado do fundo da boca.

A illação natural e logica que do exposto tiramos é que, principalment: em nosso meio em que a infecção amebiana não é tão rara, faz-se mister redobrar de attenção e cautela antes de se firmar semelhante diagnostic, ou recorrer a quem tenha mais familiaridade com estes estudos.

S. Paulo, 14 de Dezembro de 1918. 